SHARON TENNYSON AND HAE KYUNG YANG

State Prescription Drug Policies, Cost Barriers, and the Use
of Acute Care Services by Medicaid Beneficiaries

This paper examines the relationship between Medicaid pharmacy benefit restrictions and reports of prescription cost barriers by beneficiaries, and the relationship between prescription cost barriers and hospitalizations. The analysis uses data for adult Medicaid beneficiaries from the 2000-2001 and 2003 Community Tracking Survey household surveys, combined with data on states' Medicaid pharmacy benefit restrictions and characteristics of local health-care markets. Estimation results show that state Medicaid restrictions are associated with a higher incidence of reported drug cost barriers and that Medicaid recipients who report prescription cost barriers experience a greater number of hospitalizations.

Over 52 million low-income individuals receive Medicaid coverage. State and federal spending on the program amount to over $\$ 250$ billion per year, making it the largest single health insurance program in the U.S. (Kaiser Commission on Medicaid and the Uninsured 2005). Offering Medicaid prescription drug coverage is optional for states, but all states currently provide this benefit to most Medicaid beneficiaries. Medicaid provides over $\$ 30$ billion per year in prescription benefits, with over 500 million prescriptions covered (Holahan and Cohen 2006).

Research has shown that Medicaid provides similar access and use of services at levels comparable to private coverage (Dubay and Kenney 2001; Long, Coughlin, and King 2005). However, the same may not be true regarding access to prescription drugs. After controlling for health status and other characteristics, several studies have found that Medicaid beneficiaries are significantly more likely than the privately insured to report not being able to afford needed prescriptions (Berk and Schur 1998; Coughlin et al. 2005; Cunningham 2005).

Sharon Tennyson is an Associate Professor in the Department of Policy Analysis and Management at the Cornell University, Ithaca, NY (st96@cornell.edu). Hae Kyung Yang is an Assistant Professor in the Department of Political Science at the Texas Tech University, Lubbock, TX (haekyung.yang@ttu.edu).

The authors acknowledge the helpful comments of participants at the 2006 Association for Public Policy Analysis and Management meeting. The authors received funding under an unrestricted educational grant from the Merck Foundation to Cornell University.

The Journal of Consumer Affairs, Vol. 43, No. 1, 2009

ISSN 0022-0078

Copyright 2009 by The American Council on Consumer Interests 
This paper examines the consequences of states' Medicaid pharmacy benefit restrictions for beneficiary access to prescription drugs in recent years. Analysis of state policy trends over time shows that states have substantially increased access restrictions in their Medicaid programs during the past 15 years, and especially since 2000 (Crowley et al. 2005; Simon, Tennyson and Hudman 2009; Tennyson and Hudman 2007). We examine the extent to which this changing structure of Medicaid pharmacy benefits may contribute to drug cost barriers for Medicaid recipients.

Understanding whether and to what extent current state policies contribute to cost barriers among Medicaid recipients is particularly important given the pharmacy benefit program changes resulting from the passage of both Medicare Part D and the Deficit Reduction Act of 2005. Medicare Part D shifted the drug coverage of nearly six million poor elderly from Medicaid to the new Medicare plans. While these beneficiaries are exempt from the premium and deductible features of Medicare Part D, most will be subject to tiered co-payments and other access restrictions adopted by some state Medicaid plans in recent years. The Deficit Reduction Act grants states new flexibility to increase cost sharing for prescription drugs for many Medicaid beneficiaries, including children and pregnant women who are now currently exempt from cost sharing. The Deficit Reduction Act also allows states broader flexibility to deny care, including prescription drugs, to a person who is unable to meet a cost-sharing requirement. As a result of the Deficit Reduction Act, the level and scope of prescription cost-sharing requirements under states' Medicaid programs is likely to increase in the coming years.

We also examine the relationship between prescription drug access problems and hospitalizations among Medicaid beneficiaries. Prescription drugs can be viewed as an alternative to other forms of care, and drug access problems may have important negative implications for health and health-care usage. Existing research shows that failure to fill needed prescriptions may lead to greater use of other health services (Lichtenberg 1996; Piecoro et al. 2001; Sokol et al. 2005). Research has also found a significant relationship between selected Medicaid prescription drug restrictions and increased hospitalization or long-term care risk among some of the most vulnerable Medicaid populations (Soumerai et al. 1991, 1994). Examining the relationship between unmet drug needs and hospitalizations in the current environment and for the Medicaid population as a whole will provide new insights into the importance of prescription access for this population.

To explore these relationships, we analyze a two-part model of unmet prescription needs among the Medicaid population. The analysis combines 
individual-level data from the 2000-2001 and 2003 Community Tracking Study household surveys (CTS-HS) with data on states' Medicaid pharmacy benefit restrictions and characteristics of local health-care markets. We use these data to examine the relationship between states' Medicaid pharmacy benefit restrictions and cost barriers to needed prescriptions among Medicaid beneficiaries and the relationship between unmet prescription needs and hospital stays among this population.

Our empirical models incorporate individual characteristics and characteristics of the local health-care market that may be correlated with our outcome variables. We also include state fixed effects to account for permanent but unobserved differences in prescription drug cost barriers across states, and year fixed effects to allow for differences across years that affect all states equally. After controlling for these influences, our estimates show that states' policies that directly limit Medicaid drug coverage or raise the out-of-pocket costs of prescription drugs are associated with significantly greater reports of drug cost barriers among Medicaid recipients. We also find that Medicaid beneficiaries who report prescription drug cost barriers experience a higher rate of hospitalizations after controlling for other factors. These findings provide additional insights into the relationship between states' prescription drug restrictions and health outcomes of Medicaid beneficiaries.

The remainder of the paper is organized as follows. The next section discusses the existing literature on the effects of state Medicaid policies and outlines the contribution of this paper. The following section describes the data used in the empirical analysis, including states' Medicaid pharmacy benefit policies during our sample period. The fourth section of the paper discusses our empirical methods, and the subsequent two sections present the estimation results for prescription cost barriers and hospitalizations, respectively. The final section of the paper provides a brief conclusion.

\section{CONTRIBUTION OF THE STUDY}

Although a variety of studies have examined the impact of state Medicaid pharmacy benefit restrictions on drug usage or health-care utilization, most of this research examines the effect of introducing a single restriction into one state's Medicaid program, and many studies use data from earlier time periods such as the 1980s. Several studies demonstrate that drug usage by Medicaid beneficiaries is lower in states that impose co-payments (Nelson et al. 1984; Roemer et al. 1975; Stuart and Zacker 1999). Other studies find that limits on the number of prescriptions reimbursed are associated with decreased drug usage and with increased admissions to hospitals or nursing 
homes for certain high-risk populations (Martin and McMillan 1996; Soumerai et al. 1991, 1994). Similar results are found in studies of the poor and elderly in Canada (Tamblyn et al. 2001). Dranove (1989) and Moore and Newman (1993) find that Medicaid coverage of newer drugs decreased follow-up visits to doctors and hospitalizations, but increased overall costs. More recent work finds mixed evidence on the effects of Medicaid Preferred Drug Lists (PDLs) (Lichtenberg 2005; Virabhak and Shinogle 2005; Wilson, Axelsen, and Tang 2005).

In the current policy environment states are implementing many benefit restrictions and adding new measures to the set of existing policies. There has been comparatively little research into the combined effect of these pharmacy benefit restrictions on prescription drug access or use. Simon, Tennyson, and Hudman (2009) analyze the combined effect of states' prescription drug access restrictions on the growth in Medicaid prescription drug expenditures. They find that these restrictions have helped contain Medicaid prescription drug cost growth and that preferred drug lists and tiered co-payment systems may have been more effective than other policies in this regard. Cunningham (2005) examines the relationship between state Medicaid restrictions and beneficiaries' self-reported cost barriers to obtaining needed drugs. The study finds that adult Medicaid recipients in states with four or more restrictions are significantly more likely to report prescription drug cost barriers than Medicaid recipients in other states, but the effects of individual policies are largely insignificant or have unexpected signs. ${ }^{1}$

Our analysis differs by focusing on the specific policies that are most likely to generate cost barriers for needed prescription drugs. Cost barriers occur by raising out-of-pocket costs for drugs. This recognition leads us to place particular emphasis on cost sharing, coverage exclusions, and limits on prescribing, since these policies have the potential to most directly affect prescription drug affordability. We also examine the relationship between prescription drug cost barriers and hospitalizations among Medicaid beneficiaries. Because existing research has shown that adherence to drug therapy is associated with reduced hospitalization risk (Sokol et al. 2005; Piecoro et al. 2001; Lichtenberg 1996), we hypothesize that benefit restrictions may indirectly affect hospitalizations by increasing prescription drug cost barriers. Specifically, we test for a relationship between Medicaid pharmacy benefit restrictions and greater drug cost

1. States' use of prior authorization and mandatory generic substitution were the only policies found to significantly increase cost barriers in Cunningham's study. 
barriers, and between drug cost barriers and greater use of hospital inpatient services:

H1: State cost-sharing, coverage exclusions and limits on prescribing are associated with an increased likelihood that Medicaid beneficiaries are unable to obtain prescription drugs due to cost (Cost Barriers).

$\mathrm{H} 2$ : Prescription drug cost barriers are associated with larger numbers of hospital stays by Medicaid beneficiaries (Hospitalizations).

\section{DATA}

\section{Medicaid Beneficiaries}

The primary data source for our study is the household surveys of the 2000-2001 and 2003 CTS-HS. The CTS-HS is a repeated cross-sectional survey of the civilian noninstitutionalized population, conducted on a twoyear cycle by the Center for Studying Health System Change. The respondent sample is nationally representative, and the survey is conducted in sixty randomly selected communities from the contiguous forty-eight states and the District of Columbia. Alaska and Hawaii are excluded. Designed to study the changing health-care system and the effects of these changes on the community, the survey collects detailed information on respondent health status, health insurance, use of health services, and satisfaction with health care. ${ }^{2}$ The CTS-HS also collects information on a number of important demographic, health, and financial characteristics. The public use files report geographic locator information for each respondent, including state and survey site of residence. These variables allow us to link state policy data and survey site characteristics to each respondent.

Our sample consists of the adult respondents who receive health insurance benefits through Medicaid. We omit children from the sample because they are exempt from many of the state Medicaid restrictions that we study. We omit individuals who receive both Medicaid and Medicare in order to reduce sample heterogeneity that may arise due to different reasons for Medicaid eligibility. ${ }^{3}$ Respondents in Arizona and Tennessee are excluded from our study because those states provide Medicaid coverage under Section 1115 waiver programs and many of our policy measures

2. An overview of CTS survey and sampling methods can be found in Strouse et al. 2005 and Strouse et al. 2003 .

3. Estimates that include the dual-eligible respondents (the elderly poor and certain disabled individuals) are similar. 
do not apply. We also exclude respondents for whom state of residence cannot be reliably assigned. ${ }^{4}$

The resulting estimation sample contains 2,038 adult respondents residing in twenty-four states. ${ }^{5}$ The respondents in the sample are mainly single individuals, 37.4 percent without children and 34.2 percent with children. Another 19.2 percent of respondents are married with children, and 6.2 percent are married without children. The remaining 4.1 percent of respondents live in a non-nuclear family. The vast majority of respondents are between the ages of eighteen and sixty-four years, but we retain in the sample thirty-four respondents aged sixty-five years and older who are coded in the survey as receiving Medicaid but not Medicare. These respondents are otherwise very similar to the remainder of the sample (in values of both the dependent and independent variables) and our findings are not influenced by their inclusion in the sample.

Our key variables of interest are Cost Barriers and Hospitalizations. Our measure of Cost Barriers is obtained from the CTS-HS question "During the past 12 months, was there any time you needed prescription medications but didn't get them because you couldn't afford it?" "Yes" responses are coded as one and "no" responses are coded as zero, defining a dichotomous variable. Our measure of Hospitalizations is the total number of hospital stays excluding those involving childbirth, which ranges from zero to five. ${ }^{6}$ These data are obtained from a constructed variable in the CTS, based upon responses to the question "How many different times did you stay in any hospital overnight or longer during the past 12 months?", with a follow-up question to women of childbearing age regarding the number of hospital stays for the birth of a child.

Table 1 reports summary statistics for these variables along with those for relevant personal, financial, and demographic characteristics of our respondent sample. The data show that 22.13 percent of respondents experience cost barriers for needed prescription drugs during the survey period. The mean number of hospitalizations is 0.26 , with the majority of respondents having no hospital stays during the survey period. As expected, given

4. A description of state of residence recoding for some respondents can be found in section 5.1.3.4 Data switching in CTS Household Survey User's Guide, 2003.

5. Our initial sample includes 4,754 respondents who report that Medicaid is their only health insurance. We drop 2,165 respondents younger than age 18; 172 observations from Arizona and Tennessee; 209 observations for which we cannot determine the state of residence; and 170 observations that have missing data for the dependent variables in our regressions.

6. There is no available measure of number of days in hospital that excludes the number of days for childbirth. Estimates using this measure and including a control variable equal to number of births yield results that are similar to those reported here. 


\section{TABLE 1}

Summary Statistics for Regression Variables

\begin{tabular}{|c|c|c|}
\hline Variable & Mean & SD \\
\hline$\%$ Rx cost barriers & 22.13 & \\
\hline No. of hospital stays & 0.26 & 0.74 \\
\hline$\%$ Put off any needed medical care & 28.05 & \\
\hline$\%$ Changed usual source of care & 13.00 & \\
\hline No. of visits to doctor & 5.57 & 5.87 \\
\hline \multicolumn{3}{|l|}{ General health condition } \\
\hline$\%$ Excellent & 12.17 & \\
\hline$\%$ Very good & 21.79 & \\
\hline$\%$ Good & 29.83 & \\
\hline$\%$ Fair & 25.27 & \\
\hline$\%$ Poor & 10.94 & \\
\hline$\%$ Any mental health visits & 20.31 & \\
\hline Age & 35.94 & 13.34 \\
\hline$\%$ Female & 74.93 & \\
\hline \multicolumn{3}{|l|}{ Race } \\
\hline$\%$ White & 41.66 & \\
\hline$\%$ Black & 31.06 & \\
\hline$\%$ Asian and other & 6.48 & \\
\hline \% Hispanic & 20.80 & \\
\hline \multicolumn{3}{|l|}{ Usual source of care } \\
\hline$\%$ None & 11.63 & \\
\hline$\%$ Physician's office or HMO & 43.57 & \\
\hline$\%$ Clinic & 38.52 & \\
\hline$\%$ Emergency room & 6.28 & \\
\hline$\%$ Medicaid HMO & 33.17 & \\
\hline \multicolumn{3}{|l|}{ Poverty level } \\
\hline$\%$ Poverty level below $100 \%$ & 51.72 & \\
\hline$\%$ Poverty level 100-199\% & 27.58 & \\
\hline$\%$ Poverty level $200 \%+$ & 20.71 & \\
\hline \multicolumn{3}{|l|}{ Residential setting } \\
\hline$\%$ Large metro & 92.25 & \\
\hline$\%$ Small metro & 0.95 & \\
\hline$\%$ Nonmetro & 6.80 & \\
\hline \multicolumn{3}{|l|}{ Survey year } \\
\hline \% Year 2001 & 47.88 & \\
\hline \% Year 2003 & 52.12 & \\
\hline \multicolumn{3}{|l|}{ State Medicaid policies } \\
\hline$\%$ Co-payment & 71.15 & \\
\hline$\%$ Tiered co-payment & 22.13 & \\
\hline$\% \mathrm{Rx}$ limits per month & 26.64 & \\
\hline$\%$ Limits on days per $\mathrm{Rx}$ & 69.58 & \\
\hline No. drug categories not covered & 1.13 & 0.87 \\
\hline No. cost-sharing policies & 0.93 & 0.71 \\
\hline No. prescription limit policies & 0.82 & 0.77 \\
\hline No. other policies & 2.34 & 0.70 \\
\hline \multicolumn{3}{|l|}{ Local health-care markets } \\
\hline No. pharmacies per square mile & 0.83 & 1.93 \\
\hline No. physicians per capita*10 & 0.03 & 0.01 \\
\hline No. hospitals per square mile & 0.01 & 0.03 \\
\hline Number of observations & 2038 & \\
\hline
\end{tabular}

Note: Authors' calculations from CTS-HS, 2000-2001 and 2003; from Area Resource File, 2004; and from compilations of data from National Pharmaceutical Council (2001, 2003). 
the nature of the sample, respondents are relatively young, female, minority, and poor. The median respondent reports only "good" health, with 11 percent in "poor" health; just over 20 percent of respondents report at least one visit to a mental health practitioner during the year. Around 90 percent of respondents have a usual source of health care and one-third are enrolled in a Medicaid Health Maintenance Organization (HMO).

\section{State Medicaid Policies}

We combine the CTS-HS data with state Medicaid policy information. We obtain these data from Pharmaceutical Benefits under State Medical Assistance Programs, a report published annually by the National Pharmaceutical Council (NPC) and based on NPC surveys of state Medicaid program offices (NPC 2001, 2003), and from information reported by the National Council of State Legislatures. ${ }^{7}$ We compile data on each state's Medicaid pharmacy benefit restrictions for the years 2001 and 2003. We include in our database policies that attempt to reduce prescription drug expenditures by directly affecting beneficiary access to drugs (Crowley et al. 2003). Our analysis focuses primarily on cost sharing, prescribing limits, and coverage exclusions since these restrictions have the potential to directly affect out-of-pocket drug costs to beneficiaries. Because other state utilization management policies may indirectly affect drug costs, we collect data on these for use as control variables in our analysis.

Table 2 reports statistics on the scope and prevalence of the policies in each state for 2001 and 2003. The table reports the number of states using each policy, the mean value of the policy across states (for policies that have varying values), and the mean number of policies in place in each state, for each year. Overall the data show that states' use of policies varies greatly and that there is considerable change in policies between 2001 and 2003. In total thirty-three states change the number of pharmacy benefit restriction policies between 2001 and 2003. This cross-state and over-time variation will be used to identify the relationship between state policies and beneficiaries' prescription drug access.

More specifically, co-payment policies are an area of substantial change during the study period. Five states add a co-payment and eight states add a tiered co-payment policy (initiating a new co-payment or restructuring an

7. See Simon, Tennyson and Hudman (2009) for more details on the compilation of state policy data from these sources, and Kaiser Commission on Medicaid and the Uninsured (2005) for more on the characteristics of state policy restrictions. 
TABLE 2

Summary Statistics of State Medicaid Prescription Drug Policies for 2001 and 2003

\begin{tabular}{|c|c|c|c|c|c|c|c|}
\hline \multirow[b]{2}{*}{ Policy Variables } & \multirow[b]{2}{*}{ Year } & \multicolumn{2}{|c|}{ All States } & \multicolumn{4}{|c|}{$\begin{array}{l}\text { States with } \\
\text { the Policy }\end{array}$} \\
\hline & & $\begin{array}{l}\text { States with } \\
\text { the Policy }\end{array}$ & $\begin{array}{l}\text { States without } \\
\text { the Policy }\end{array}$ & Mean & SD & Min. & Max. \\
\hline \multirow[t]{2}{*}{ Co-payment } & 2001 & 33 & 16 & $\$ 1.86$ & $\$ 0.84$ & $\$ 0.50$ & $\$ 3.00$ \\
\hline & 2003 & 38 & 11 & $\$ 2.50$ & $\$ .09$ & $\$ 1.00$ & $\$ 5.00$ \\
\hline \multirow[t]{2}{*}{ Tiered co-payment } & 2001 & 6 & 43 & $\$ 2.33$ & $\$ 0.82$ & $\$ 1.00$ & $\$ 3.00$ \\
\hline & 2003 & 14 & 35 & $\$ 2.93$ & $\$ 0.73$ & $\$ 2.00$ & $\$ 5.00$ \\
\hline \multirow[t]{2}{*}{ Limit on Rx per month } & 2001 & 11 & 38 & 5.21 & 2.61 & 3 & 10 \\
\hline & 2003 & 14 & 35 & 4.72 & 1.52 & 3 & 10 \\
\hline \multirow{2}{*}{$\begin{array}{l}\text { Limit on quantity } \\
\text { per Rx (days) }\end{array}$} & 2001 & 42 & 7 & 41.78 & 23.87 & 30 & 100 \\
\hline & 2003 & 43 & 6 & 39.07 & 19.00 & 30 & 100 \\
\hline \multirow{2}{*}{$\begin{array}{c}\text { Drug categories } \\
\text { not covered }\end{array}$} & 2001 & 35 & 12 & 1.60 & 0.74 & 1.00 & 3.00 \\
\hline & 2003 & 34 & 14 & 1.56 & 0.70 & 1.00 & 3.00 \\
\hline \multirow{2}{*}{$\begin{array}{l}\text { No. of cost } \\
\quad \text { and limit policies }\end{array}$} & 2001 & & & 2.59 & 0.98 & 1.00 & 3.00 \\
\hline & 2003 & & & 2.92 & 1.04 & 1.00 & 3.00 \\
\hline \multirow[t]{2}{*}{ No. of other policies } & 2001 & & & 1.88 & 0.73 & 0.00 & 3.00 \\
\hline & 2003 & & & 2.51 & 0.77 & 1.00 & 4.00 \\
\hline \multirow[t]{2}{*}{ No. of total policies } & 2001 & & & 4.47 & 1.28 & 2.00 & 8.00 \\
\hline & 2003 & & & 5.43 & 1.43 & 2.00 & 8.00 \\
\hline
\end{tabular}

Note: Authors' calculations from National Pharmaceutical Council and National Council on State Legislators data. Arizona and Tennessee are omitted from the sample.

existing co-payment) between 2001 and 2003. Among the thirty-three states with a co-payment in 2001, fourteen of those change the maximum co-payment amount. The average value of the maximum co-payment is $\$ 1.86$ in 2001 and $\$ 2.50$ in 2003.

Medicaid law requires that states provide coverage for all Food and Drug Administration-approved medications for which pharmaceutical manufacturers have rebate agreements in effect with the federal government. There are, however, nine categories of exceptions for which states have the right to deny or limit coverage. Nearly all states provide coverage for most of these drug categories, but a majority of states exclude coverage of at least one of the categories. The number of states excluding at least one drug category is thirty-five in 2001 and thirty-four in 2003. Among the states that have restrictions in place in both 2001 and 2003, two states increase the stringency of restrictions, adding an average of 1.5 new drug categories to the list of excluded drugs; five states decrease existing restrictions, removing an average of 1.2 drug categories from the list of exclusions.

States may also restrict prescription coverage for each beneficiary, including limiting the number of prescriptions per month, the number 
of refills allowed or the quantity of pills in each prescription. ${ }^{8}$ In 2001, eleven states restrict the number of prescriptions per month; between 2001 and 2003 four states add new limits on the number of prescriptions, and one state eliminates prescription limits, leaving fourteen states with prescription limits in 2003. In 2001, forty-two states restrict the number of pills per prescription, and this number rises to forty-three states by 2003. None of the states with prescription limits already in place in 2001 change the limit amounts over this time period.

In addition to cost sharing, drug exclusions and prescribing limits, many states employ utilization management policies to shift drug use toward specific drugs or types of drugs (generally less expensive ones). Utilization management policies include mandatory substitution of generic drugs for brand name drugs; prior authorization requirements; fail-first protocols that allow use of newer therapies only after older therapies have been shown to fail; and preferred drug lists that make certain drugs available without prior authorization. Utilization management policies are not the main focus of our analysis because they have the effect of shifting use between drugs or drug categories, and are likely to have no effect on (or will reduce) out-of-pocket drug costs to beneficiaries. However, for completeness, we compile data on the prevalence of these four policies. Our data show that states use an average of 1.88 of these policies in 2001 and an average of 2.51 in 2003.

\section{Other Data}

We add to the data set selected variables from the Area Resource File 2004 release, to incorporate relevant characteristics of the health-care market for each CTS survey site. The Area Resource File is collected annually by the Bureau of Health Professions in the Department of Health and Human Services and reports county level information regarding the health professions, health facilities, and populations, among other variables. We construct variables at the CTS site level by summing Area Resource File data over the counties within each site. Summary statistics of the Area Resource File variables for our sample of Medicaid beneficiaries are included in Table 1.

8. We do not consider refill limits because most states' refill limits apply only over a time period, such as five refills per six-month period, and thus should not raise costs for beneficiaries. In addition, National Pharmaceutical Council data are less clear regarding refill limits leading to concerns about comparability of reported limits across states. 


\section{EMPIRICAL METHODS}

We test $\mathrm{H} 1$ and $\mathrm{H} 2$ defined above using econometric models that control for individuals' demographic, financial and health characteristics, and the characteristics of local health-care markets. Based on prior research, which suggests that lack of prescription drug adherence leads to increased hospitalizations, we estimate a two-part model of the effect of state Medicaid prescription drug restrictions:

$$
\begin{aligned}
\text { Cost }_{\text {Barriers }}{ }_{i s t}= & a_{0}+a_{1} \text { State Restrictions }_{s t}+\Delta X_{i s t}+\gamma S_{1 s} \\
+ & v T_{1 t}+\varepsilon_{1 i s t} \\
\text { Hospitalizations }_{i s t}= & \beta_{0}+\beta_{1} \text { Cost Barriers } \\
& +\Pi W_{i s t}+\gamma S_{2 s}+v T_{2 t}+\varepsilon_{2 i s t}
\end{aligned}
$$

where the subscript $i$ denotes the individual, $s$ denotes the individual's state of residence and $t$ denotes year. Cost Barriers ist $_{\text {is }}$ a dichotomous variable set equal to one if an individual reports reduced access to prescription drugs due to cost, and set equal to zero otherwise. Hospitalizations $i_{i s t}$ is the number of hospital stays per year excluding stays for childbirth. State Restrictions $_{s t}$ is a measure of Medicaid pharmacy benefit policies in force in the individual's state of residence $s$ in time $t . X_{i s t}$ and $W_{i s t}$ are vectors of other explanatory (control) variables. $S$ is a vector of state indicators and $T$ is a vector of year indicators, and $\varepsilon_{i s t}$ is a random error term.

For ease of interpretation, we present linear probability models of prescription cost barriers; results using probit methods are similar. For the hospitalizations models, we present estimation results using both ordinary least squares (OLS) and negative binomial (NB) regression methods because NB methods may be more appropriate when the dependent variable takes on discrete integer values, and the interpretation of OLS and NB estimates differs. ${ }^{9}$ Coefficients in the OLS models represent the estimated impact of independent variables on the number of hospitalizations, while coefficients in the NB models represent the estimated percentage change in number of hospitalizations resulting from changes in the independent variables.

9. Because a large majority of individuals report either zero hospital stays for the year or one stay, we also estimate probit models in which the dependent variable is set equal to one if the respondent reported any (one or more) hospitalizations. Results show significant effects of prescription cost barriers on the probability of one or more hospital stays. 
We also explore models that allow for prescription cost barriers and hospital stays to be jointly determined. We approach this by estimating equation (2) as above but treating Cost Barriers ${ }_{i s t}$ as an endogenous dummy variable. Using this method, based on Heckman (1978) and using maximum likelihood methods as described in Maddala (1983), Cost Barriers $_{i s t}$ is modeled as the outcome of the exogenous covariates in equation (1). The error terms $\varepsilon_{1 i s t}$ and $\varepsilon_{2 i s t}$ are assumed to have a bivariate normal distribution with mean zero, variance one and $\sigma$ respectively, and covariance $\rho$.

\section{STATE POLICIES AND PRESCRIPTION COST BARRIERS}

\section{Model Specification}

The key explanatory variable of interest in equation (1) is Restrictions ${ }_{s t}$, a measure of Medicaid cost and limit restrictions in the individual's state of residence $\mathrm{s}$ at time $t$. Our measures of state restrictions include the state's co-payment system (including tiering), limits on prescriptions (number of prescriptions per month and number of pills per prescription), and the number of drug classes for which prescriptions are not covered. All models also include as a control variable the number of utilization management policies used by the state.

Our models include multiple policies and each state may have a number of these in place, raising concerns about multicollinearity among the policy measures. Thus, we estimate three alternative specifications that include different ways of grouping and measuring the policy variables. The first includes the counts of each distinct type of policy: the number of cost-sharing policies (co-pay and tiered co-pay), the number of prescription limit policies (prescriptions per month and pills per prescription), the number of drug categories excluded from coverage, and the number of utilization management policies in each state and year. The second includes separate indicator variables for each cost sharing and prescription limit policy, along with the number of drug categories excluded and the number of utilization management policies. The third includes measures of the stringency of cost and limit policies - an indicator set equal to one if the state has a high maximum co-payment, and an indicator set equal to one if the state imposes limits on both prescriptions per month and pills per prescription-along with the number of drug categories excluded and the number of utilization management policies. The high co-payment indicator is set equal to one if the value of the maximum co-payment is in the top quartile of states. 
Examination of the estimated variance inflation factors (VIF) in each of these model specifications shows variance inflation factors substantially less than 10, indicating the absence of significant multicollinearity concerns (Belsley, Kuh and Welsch 1980).

Other control variables included in the models account for demographic, health, and financial characteristics of an individual that may be correlated with drug cost barriers. These include race, gender, age, age squared, income, and health status. Income and health status are particularly important since those with fewer financial resources will be less able to afford needed prescriptions and individuals in poorer health may report greater cost barriers simply because they have a larger number of needed prescriptions. Thus, we include family income in relation to the poverty level (at the relevant family size), self-reported general health status, and an indicator variable for any mental health visits.

The models also include individual-level variables to measure access to routine health-care services. These include the nature of the individual's usual source of care, if any, and whether the individual is insured through a Medicaid managed care organization. Coded choices for usual source of care are doctor's office/HMO, hospital outpatient clinic/other health center/ other place, and emergency room; the excluded category is no usual source of care. The Medicaid managed care indicator captures any effects of managed care on drug access (whether increased through case management or decreased through utilization requirements).

In keeping with economic theories of the demand for health care (Grossman 1972; Fuchs 1982), we recognize that use of health-care services reflects individual choices regarding the allocation of limited resources toward health care versus other goods. As a result, two individuals with identical income, health and care access may demand different amounts of care and may perceive different degrees of prescription affordability problems. Although demographic characteristics may partially control for these differences, we include indicators of the respondent's continuing relationship with care providers-whether the respondent delayed seeking medical services for any health-care needs, and whether the respondent changed his/her usual source of care-as additional controls. These variables measure gaps in the respondent's health-care access, but because they are choice-based they may also reflect the individual's attitudes regarding the relative importance of health care. For both of these reasons, we expect that respondents who report putting off medical care or changing their source of care will be more likely to report that they did not obtain needed prescriptions due to cost. Additionally, in some models, we include the number of visits to a doctor as a direct measure of health-care utilization. 
After controlling for health-care status, this variable reflects the demand for health care, and also controls for the fact that reporting an inability to afford needed prescriptions may be premised on first obtaining a prescription from a health-care provider. For these reasons, we expect the number of doctor visits to be positively associated with prescription cost barriers.

Additional site-level variables are included in the models to measure access to pharmacy services since higher prices (including costs of time or travel) for prescription drugs will also raise cost barriers. We include the number of pharmacies per square mile in the individual's resident site to proxy for average drug prices (including travel costs), and metropolitan area size indicators to control for other differences in health-care environments that may be related to market size.

\section{Estimation Results}

Table 3 reports the results of estimation. All models include state and year indicators. Reported standard errors are robust to both arbitrary forms of heteroskedasticity and arbitrary correlation of errors across years within each state. The first set of models reported include the state policy counts, the second set of models include separate variables for each state policy, and the third set include the measures of state cost sharing and prescription limit stringency. To preserve space, coefficient estimates for the demographic, financial, and health variables are not reported in Table 3. ${ }^{10}$

All estimates demonstrate that states' Medicaid prescription drug copayment policies are positively and significantly related to beneficiary reports of prescription cost barriers. Whether measured as the number of co-payment policies, co-payment and tiered co-payment policies separately, or an indicator of a higher co-payment amount, co-payments are positively related to prescription cost barriers. The number of drug categories not covered in a state is also positively related to drug cost barriers in all model specifications. Prescription limit policies (whether number per month or days per prescription) and the utilization management policies are not significantly related to prescription cost barriers.

As hypothesized, respondents who report delays in seeking needed medical care are more likely to report prescription cost barriers, as are

10. Coefficient estimates for these variables are consistent with expectations. Prescription cost barriers increase with age and decrease with income. The relative incidence of prescription cost barriers increases with decreases in reported health, and a mental health diagnosis has a large positive impact on reported cost barriers. Those whose usual source of care is a clinic report lower prescription cost barriers. 


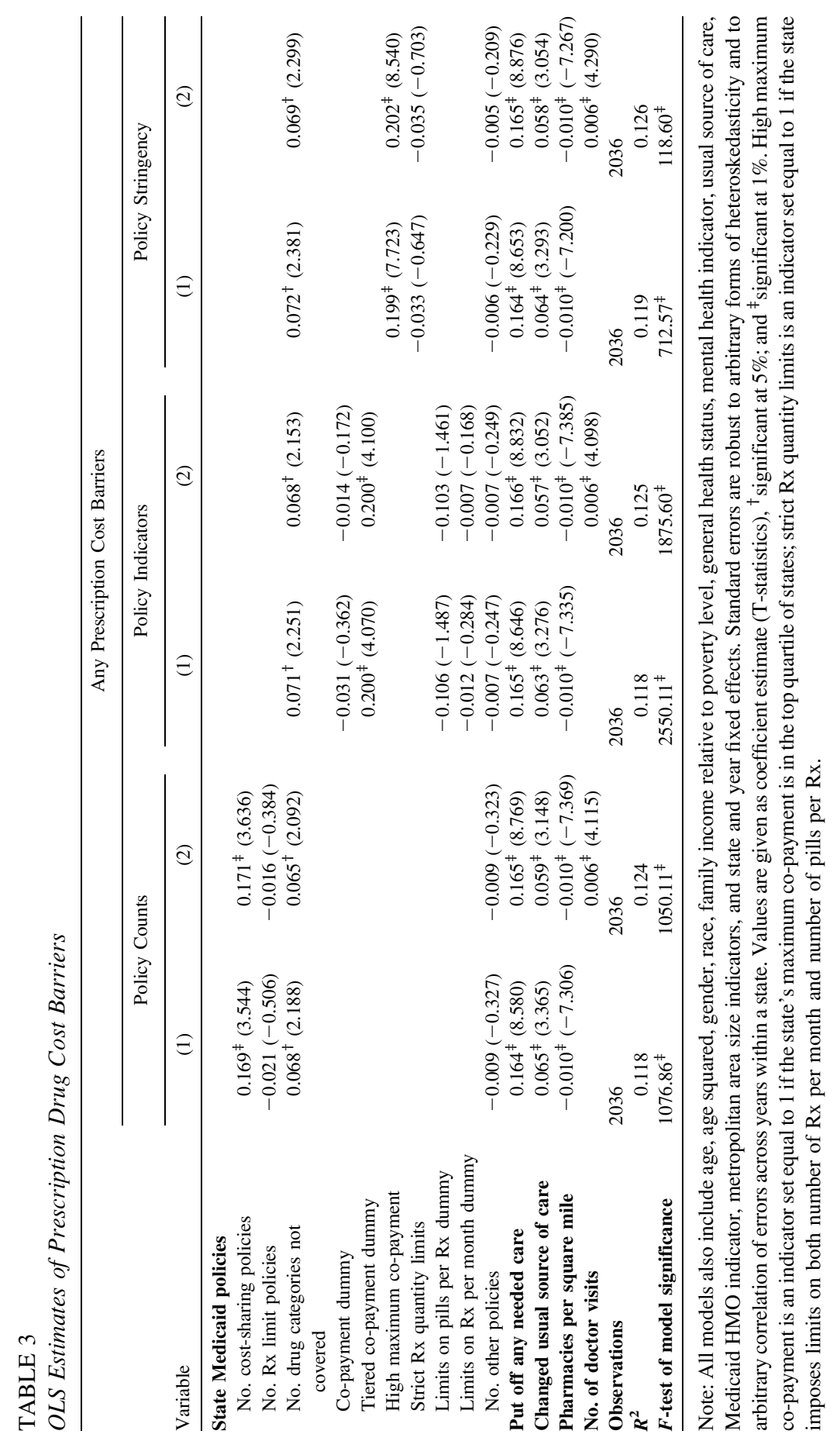


respondents who changed their usual source of care. The number of doctor visits is also associated with greater prescription cost barriers. The number of pharmacies per square mile in an individual's city of residence has a negative and significant impact on cost barriers, consistent with the interpretation that greater access to pharmaceuticals leads to lower prescription drug cost barriers.

The estimated impact of state Medicaid restrictions is nontrivial. A larger number of cost-sharing restrictions is associated with a $17 \%$ higher likelihood of prescription cost barriers, which translates to a 3.8 percentage point increase-from the sample mean of $22.4 \%$ - in the fraction of respondents reporting cost barriers-to $26.2 \%$. Similarly, a larger number of drug categories not covered is associated with a $7 \%$ greater likelihood of prescription cost barriers, or a 1.6 percentage point increase in the fraction of respondents reporting cost barriers (to 24.0\%). States with a tiered co-payment or a co-payment amount that falls among the highest quartile of states have reported cost barriers that are $20 \%$ greater, which implies a 4.4 percentage point increase in respondents reporting cost barriers (to $26.8 \%$ ). Overall, the results imply that co-payments and drug exclusions are associated with substantially higher prescription cost barriers among adult Medicaid beneficiaries.

\section{DRUG COST BARRIERS AND HOSPITALIZATIONS}

\section{Model Specification}

The key explanatory variable of interest in the model of hospitalizations is Cost Barriers ${ }_{i s t}$, the self-reported measure of inability to obtain needed drugs due to cost. We hypothesize that prescription cost barriers will be positively related to the number of hospital stays. Control variables in the model include individual-level variables to reflect the fact that hospitalization risk will depend on underlying health, individual demographics, and access to nonacute health-care services. Poorer underlying health will lead to greater risk of hospitalization holding all other characteristics fixed. Demographic characteristics may play a role because of their influence on the ability to avoid, resist, or recover from illness or injuries. Other individual characteristics such as race and income may also influence hospitalization risk if these affect overall health status, the use of nonacute care services, or attitudes toward consumption of medical services in general. The demographic, health, and financial characteristics we use are the same variables included in the models of prescription cost barriers. 
The models also include the individual-level and site-level measures of access to routine health care. Greater access to regular health-care services, including having a usual source of care, has been shown to reduce the risk of hospitalization (Heisler et al. 2004; Klein et al. 2004). The individual measures are those included in the cost barriers models-the usual source of care and an indicator of insurance through Medicaid managed care. Additional model specifications include the indicators of delayed medical care and of a change in usual source of care, along with the number of visits to a doctor. Site-level variables to measure access to hospital services are the number of hospitals per square mile and the number of doctors per capita. Metropolitan area size indicators are included in the models to control for other unobserved differences in health-care environments that may be related to market size.

\section{Estimation Results}

Table 4 reports the OLS and NB estimates of the number of hospital stays. All models include state and year fixed effects, and standard errors that are robust to arbitrary forms of heteroskedasticity; in the OLS models errors are also robust to arbitrary correlation of errors across years within each state. As in the previous table, the demographic, financial, and health variables are not reported. ${ }^{11}$

In all specifications, prescription drug cost barriers are positive and significantly related to the number of hospital stays, consistent with previous research findings that reduced health-care access leads to greater hospitalization risk. The number of hospitals per square mile is also positive and significant in all models, suggesting that availability of hospital services is associated with more hospital stays. A greater number of doctor visits are associated with a greater number of hospital stays, likely due to the effects of poorer health. However, the measures of gaps in health-care accessdelays in seeking medical care and any change in the usual source of care-are not significantly related to hospitalizations.

As noted previously, the interpretation of coefficients differs across OLS and NB estimation methods. Coefficients in the OLS models represent the estimated impact of prescription cost barriers on the number of hospitalizations, while coefficients in the NB models represent the estimated percentage change in number of hospitalizations resulting from prescription cost

11. In all models, respondents with worse health status experience more hospital stays than those reporting better health. In most models, respondents with a mental health diagnosis have more hospital stays than others. Hispanics have fewer hospital stays than others. 
TABLE 4

OLS and NB Estimates of Hospital Stays

\begin{tabular}{|c|c|c|c|c|c|c|}
\hline \multirow[b]{3}{*}{ Variable } & \multicolumn{6}{|c|}{ Number of Hospital Stays } \\
\hline & \multicolumn{3}{|c|}{ OLS Models } & \multicolumn{3}{|c|}{ NB Models } \\
\hline & (1) & (2) & (1) & (2) & (1) & (2) \\
\hline $\begin{array}{l}\text { Prescription } \\
\text { cost barriers }\end{array}$ & $\begin{array}{c}0.125^{\ddagger} \\
(3.789)\end{array}$ & $\begin{array}{c}0.125^{\ddagger} \\
(4.080)\end{array}$ & $\begin{array}{c}0.104^{\ddagger} \\
(3.436)\end{array}$ & $\begin{array}{c}0.483^{\ddagger} \\
(3.602)\end{array}$ & $\begin{array}{c}0.459^{\ddagger} \\
(3.356)\end{array}$ & $\begin{array}{r}0.421^{\ddagger} \\
(3.084)\end{array}$ \\
\hline $\begin{array}{l}\text { Hospitals per } \\
\text { square mile }\end{array}$ & $\begin{array}{c}0.899^{\ddagger} \\
(3.465)\end{array}$ & $\begin{array}{c}0.871^{\ddagger} \\
(3.222)\end{array}$ & $\begin{array}{l}0.825^{\ddagger} \\
(3.354)\end{array}$ & $\begin{array}{l}5.209 * \\
(1.893)\end{array}$ & $\begin{array}{c}5.135^{*} \\
(1.942)\end{array}$ & $\begin{array}{r}5.232 * \\
(1.938)\end{array}$ \\
\hline $\begin{array}{l}\text { Physicians } \\
\text { per capita }\end{array}$ & $\begin{array}{l}15.768 \\
(0.852)\end{array}$ & $\begin{array}{l}17.885 \\
(1.003)\end{array}$ & $\begin{array}{r}21.046 \\
(1.051)\end{array}$ & $\begin{array}{r}113.198 \\
(0.872)\end{array}$ & $\begin{array}{r}119.664 \\
(0.914)\end{array}$ & $\begin{array}{r}123.109 \\
(0.918)\end{array}$ \\
\hline $\begin{array}{l}\text { Put off any } \\
\text { needed care }\end{array}$ & & $\begin{array}{l}-0.015 \\
(-0.542)\end{array}$ & $\begin{array}{l}-0.009 \\
(-0.344)\end{array}$ & & $\begin{array}{r}0.024 \\
(0.171)\end{array}$ & $\begin{array}{r}0.056 \\
(0.410)\end{array}$ \\
\hline $\begin{array}{l}\text { Changed usual } \\
\text { source of care }\end{array}$ & & $\begin{array}{r}0.059 \\
(0.850)\end{array}$ & $\begin{array}{r}0.420 \\
(0.597)\end{array}$ & & $\begin{array}{r}0.285 \\
(1.658)\end{array}$ & $\begin{array}{r}0.279 \\
(1.571)\end{array}$ \\
\hline $\begin{array}{l}\text { No. of doctor } \\
\text { visits }\end{array}$ & & & $\begin{array}{c}0.018^{\ddagger} \\
(4.878)\end{array}$ & & & $\begin{array}{r}0.068^{\ddagger} \\
(6.825)\end{array}$ \\
\hline Observations & 2038 & 2038 & 2038 & 2038 & 2036 & 2036 \\
\hline$R^{2}$ & 0.096 & 0.097 & 0.114 & & & \\
\hline $\begin{array}{l}\text { Wald- } \chi^{2} \\
\text { statistic }\end{array}$ & & & & $203.51^{\ddagger}$ & $2185.60^{\ddagger}$ & $2122.34^{\ddagger}$ \\
\hline
\end{tabular}

Note: All models also include age, age squared, gender, race, family income relative to poverty level, general health status, mental health indicator, usual source of car, Medicaid HMO indicator, metropolitan area size indicators, and state and year fixed effects. Standard errors are robust to arbitrary heteroskedasticity and in OLS models to arbitrary correlation within state. Values are given as coefficient estimates ( $T$-statistics) in OLS models and coefficient estimates ( $z$-statistics) in NB models, *significant at $10 \%$ confidence level; ${ }^{\dagger}$ significant at $5 \%$; and ${ }^{\ddagger}$ significant at $1 \%$.

barriers. The estimated OLS parameter value of 0.125 suggests that prescription cost barriers increase the mean number of hospitalizations from 0.26 to 0.385 . The NB parameter value of 0.483 suggests that prescription cost barriers increase the mean number of hospitalizations by $48.3 \%$ (from 0.26 to 0.386). Thus, the OLS and NB estimates imply similar effects.

Although theory and previous research suggest a directional effect leading from prescription cost barriers to more hospitalizations, it is possible that causality could run in the opposite direction. That is, hospital stays could result in a greater number of needed prescriptions, which in turn could increase prescription affordability problems. Thus, we explore the effects of treating Cost Barriers ${ }_{i s t}$ and Hospitalizations $s_{i s t}$ as jointly determined. These estimates treat Cost Barriers ${ }_{i s t}$ as an endogenous dummy vari-

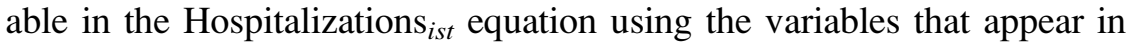
the Cost Barriers ist $_{\text {equation but not in the Hospitalizations }}$ ist equation to identify the system.

The estimation results are reported in Table 5. Note that the endogenous dummy variable estimates use a linear specification for Hospitalizations ist 
and thus should be compared to the OLS estimates reported previously. The results show substantial similarity to those in Table 4. Specifically, prescription cost barriers remain positive and significantly related to hospitalizations in all specifications, and the estimated coefficient magnitudes are about the same as those in the OLS models. The statistical significance of the estimated parameter on Cost Barriers ${ }_{i s t}$, is generally lower in these models, but remains significant at better than the $10 \%$ confidence level in all specifications. One further note of interest is that the Wald test of independence of the cost barriers and hospitalizations equations fails to reject the hypothesis that the equations are independent (i.e., the hypothesis that $\rho=0$ cannot be rejected).

The estimation results linking prescription cost barriers to hospitalizations appear robust but are subject to a caveat that arises due to the structure of the dataset. The CTS-HS survey asks respondents at a point in time about their health-care usage over the entire past year. Individuals who are less healthy may need both more prescription drugs and more acute care services during the year. Thus, it is possible that instead of being causally related, prescription cost barriers and hospitalizations are both driven by the same (unobservable) factors. Our empirical models control for a wide variety of demographic, health, and personal characteristics; health-care access and characteristics of local health-care markets; along with Metropolitan Statistical Area (MSA), state, and year fixed effects in order to reduce the likelihood of this problem. However, because the CTS-HS does not follow individuals over time we cannot completely rule out this possibility in our study.

\section{TABLE 5}

Endogenous Dummy Variable Estimates of Hospital Stays

\begin{tabular}{lccc}
\hline Variable & \multicolumn{3}{c}{ Number of Hospital Stays } \\
\hline Prescription cost barriers & $0.124^{*}(1.812)$ & $0.121^{\dagger}(2.057)$ & $0.106^{*}(1.839)$ \\
Hospitals per square mile & $0.898(1.239)$ & $0.869(1.209)$ & $0.827(1.149)$ \\
Physicians per capita & $15.790(0.514)$ & $17.876(0.582)$ & $21.054(0.685)$ \\
Put off any needed care & & $-0.014(-0.355)$ & $-0.010(-0.246)$ \\
Changed usual source of care & & $0.059(1.080)$ & $0.042(0.759)$ \\
No. of doctor visits & 2036 & 2036 & $0.018^{\ddagger}(4.762)$ \\
Observations & $147.97^{\ddagger}$ & $148.580^{\ddagger}$ & 2036 \\
Wald- $\chi^{2}$ statistic & 0.001 & 0.003 & $162.080^{\ddagger}$ \\
Estimated value of $\rho$ & & & -0.002 \\
\hline
\end{tabular}

All models also include age, age squared, gender, race, family income relative to poverty level, general health status, mental health indicator, usual source of care, Medicaid HMO indicator, metropolitan are size indicators, and state and year fixed effects. Values are given as coefficient estimates ( $T$-statistics) in OLS models and coefficient estimates ( $z$-statistics) in NB models, *significant at $10 \%$ confidence level ${ }^{\dagger}$ significant at $5 \%$; and ${ }^{\ddagger}$ significant at $1 \%$. 


\section{CONCLUSION}

Our study uses a general population of Medicaid beneficiaries to examine the relationship between Medicaid pharmacy benefit restrictions and the incidence of prescription drug cost barriers. We examine the impact of state prescription drug policies that have the potential to directly increase out-ofpocket drug costs for Medicaid beneficiaries. These include co-payments, limits on prescribing and drug category exclusions. We also examine the relationship between unmet prescription needs and hospitalizations among the Medicaid population.

Our estimates show that co-payments and drug category exclusions are associated with a statistically significant and economically important increase in the prevalence of prescription cost barriers among adult Medicaid beneficiaries. We also find that, for this population, experiencing prescription cost barriers is associated with a greater number of hospital stays. These results are consistent with previous studies that find the use of prescription drugs by Medicaid beneficiaries is lower in states that impose stricter benefit restrictions and that link this lower use to negative health consequences or the use of more costly health-care services. In redesigning Medicaid policies under the rules allowed by Deficit Reduction Act of 2005, states should be aware of the potential for certain types of restrictionsespecially higherco-payments - to create cost barriers to needed prescription drugs since this may lead to negative effects on health and health-care utilization.

\section{REFERENCES}

Belsley, D., E. Kuh, and R.E. Welsch. 1980. Regression Diagnostics. New York: John Wiley \& Sons. Berk, Mark L. and Claudia Schur. 1998. Access to Care: How Much Difference Does Medicaid Make? Health Affairs, 17 (3): 169-180.

Bound, J., D.A. Jaeger, and R.M. Baker. 1995. Problems with Instrumental Variable Estimation when the Correlation between the Instruments and the Endogenous Explanatory Variable is Weak. Journal of the American Statistical Association, 90: 443-450.

Crowley, Jeffrey, Deb Ashner, and Linda Elam. 2003. Medicaid Outpatient Prescription Drug Benefits: Findings from a National Survey, 2003. Report. Washington, DC: The Kaiser Commission on Medicaid and the Uninsured.

-2005. State Medicaid Outpatient Prescription Drug Policies: Findings from a National Survey, 2005 Update. Report. Washington, DC: The Kaiser Commission on Medicaid and the Uninsured.

Cunningham, Peter. 2005. Medicaid Cost Containment and Access to Prescription Drugs. Health Affairs, 24 (3): 780-790.

Dranove, David. 1989. Medicaid Drug Formulary Restrictions. Journal of Law and Economics, 32 (1): $143-162$.

Fuchs, Victor R. 1982. Time Preference and Health: An Exploratory Study. In Economic Aspects of Health, edited by V.R. Fuchs (93-120). Chicago, IL: University of Chicago Press for the National Bureau of Economic Research. 
Grossman, Michael. 1972. The Demand for Health: A Theoretical and Empirical Investigation. New York: Columbia University Press for the National Bureau of Economic Research.

Heckman, James J. 1978. Dummy Endogenous Variables in a Simultaneous Equation System. Econometrica, 46 (6): 931-59.

Holahan, John and Mindy Cohen. 2006. Cover Missouri Project 4: Missouri Medicaid Spending Growth 2001-2005. www.urban.org/UploadedPDF/1001004_CoverMo4.pdf

Heisler, Michele, Kenneth M. Langa, Elizabeth L. Eby, A. Mark Fendrick, Mohammed V. Kabeto, and John D. Piette. 2004. The Health Effects of Restricting Prescription Medication Use because of Cost. Medical Care, 42 (7): 626-634.

Kaiser Commission on Medicaid and the Uninsured. 2005. The Medicaid Program at a Glance. Fact Sheet. Washington, DC: The Kaiser Commission on Medicaid and the Uninsured.

Klein, Dawn, Carolyn Turvey, and Robert Wallace. 2004. Elders Who Delay Medication because of Cost: Health Insurance, Demographic, Health and Financial Correlates. The Gerontologist, 44 (6): 779-787.

Lichtenberg, Frank R. 1996. The Effect of Pharmaceutical Utilization and Innovation on Hospitalization and Mortality. NBER Working Paper No. 5218.

- 2005. The Effect of Access Restrictions on the Vintage of Drugs Used by Medicaid Enrollees. American Journal of Managed Care, 11 (Special Issue): SP7-SP13.

Long, Sharon K., Teresa A. Coughlin, and Jennifer King. 2005. How Well Does Medicaid Work in Improving Access to Care? Health Services Research, 40 (1): 39-58.

Maddala, G.S. 1983. Limited-Dependent and Qualitative Variables in Econometrics. Cambridge: Cambridge University Press.

Martin, Bradley C. and John A. McMillan. 1996. The Impact of Implementing a More Restrictive Prescription Limit on Medicaid Recipients. Effects on Cost, Therapy and Out-of-Pocket Expenditures. Medical Care, 34 (7): 686-700.

Moore, William and Robert J. Newman. 1993. Drug Formulary Restrictions as a Cost-Containment Policy in Medicaid Programs. Journal of Law \& Economics, 36 (1): 71-97.

National Pharmaceutical Council. 2001, 2003. Pharmaceutical Benefits under State Assistance Programs, Annual Reports. Reston, VA: National Pharmaceutical Council.

Nelson, Arthur A., Eugene C. Reeder, and W. Michael Dickson. 1984. The Effect of a Medicaid Drug Copayment Program on the Utilization and Cost of Prescription Services. Medical Care, 22 (8): 724-735.

Piecoro, Lance T., Matthew Potoski, Jeff C. Talbert, and Dennis E. Doherty. 2001. Asthma Prevalence, Cost, and Adherence with Expert Guidelines on the Utilzation of Health Care Services and Costs in a State Medicaid Population. Health Services Research, 36 (2): 357-371.

Roemer, Milton I., Carl E. Hopkins, Lockwood Carr, and F. Gartside. 1975. Copayments for Ambulatory Care: Penny-wise and Pound-foolish. Medical Care, 13 (6): 457-466.

Simon, Kosali, Sharon Tennyson, and Julie Hudman. 2009. Do State Cost Control Policies Reduce Medicaid Prescription Drug Spending? Risk Management and Insurance Review, 12 (1): 37-64.

Sokol, Michael C., Kimberly A. McGuigan, Robert R. Verbrugge, and Robert S. Epstein. 2005. Impact of Medication Adherence on Hospitalization Risk and Healthcare Cost. Medical Care, 43 (6): 517-520.

Soumerai, Stephen B, Dennis Ross-Degnan, J Avorn, Thomas J. McLaughlin, and Igor Choodnovskiy. 1991. Effects of Medicaid Drug-Payment Limits on Admission to Hospitals and Nursing Homes. The New England Journal of Medicine, 325 (15): 1072-1077.

Soumerai, Stephen B., Thomas J. McLaughlin, Dennis Ross-Degnan, Christina S. Casteris, and Paola Bollini. 1994. Effects of Limiting Medicaid Drug-Reimbursement Benefits on the Use of Psychotropic Agents and Acute Mental Health Services by Patients with Schizophrenia. The New England Journal of Medicine, 331 (10): 650-655.

Strouse, Richard, Barbara Carlson, and John Hall. 2003. Community Tracking Study Household Survey Methodology Report 2000-01 (Round Three). Technical Publication No. 46. Washington, DC: Center for Studying Health System Change.

- 2005. Community Tracking Study Household Survey Methodology Report 2003 (Round Four). Technical Publication No. 62. Washington, DC: Center for Studying Health System Change. 
Stuart, Bruce and Christopher Zacker. 1999. Who Bears the Burden of Medicaid Drug Copayment Polices? Health Affairs, 18 (2): 201-212.

Tamblyn, Robyn, Rejean Laprise, James A. Hanley, Michael Abrahamowicz, Susan S. Scott, Nancy Mayo, Jerry Hurley, Roland Grad, Eric Latimer, Robert Perreault, Peter McLeod, Allen Huang, Pierre Larochelle, and Louise Mallet. 2001. Adverse Events Associated with Prescription Drug Cost-Sharing among Poor and Elderly Persons. Journal of American Medical Association, 285 (4): 421-429.

Virabhak, Suchin and Judith A. Shinogle. 2005. Physicians' Prescribing Responses to a Restricted Formulary: The Impact of Medicaid Preferred Drug Lists in Illinois and Louisiana. American Journal of Managed Care, 11 (Special Issue): SP14-SP20.

Wilson, Jerome, Kirsten Axelsen, and Simon Tang. 2005. Medicaid Prescription Drug Access Restrictions: Exploring the Effect on Patient Persistence with Hypertension Medications. American Journal of Managed Care, 11 (Special Issue): SP27-SP34. 